\title{
Dealing with resistance to the use of Industry 4.0 technologies in production disturbance management
}

\author{
Adriana Ito and Torbjörn Ylipää \\ Chalmers University of Technology, Gothenburg, Sweden \\ Per Gullander \\ RISE Research Institutes of Sweden AB, Mölndal, Sweden \\ Jon Bokrantz \\ Chalmers University of Technology, Gothenburg, Sweden \\ Victor Centerholt \\ RISE Research Institutes of Sweden AB, Mölndal, Sweden, and \\ Anders Skoogh \\ Chalmers University of Technology, Gothenburg, Sweden
}

\begin{abstract}
Purpose - Resistance is expected to emerge with the implementation and use of new technologies in production systems. This work focuses on identifying sources of resistance to the use of Industry 4.0 technologies when managing production disturbances and suitable managerial approaches to deal with them. Design/methodology/approach - A qualitative approach was chosen in this research. The authors conducted a literature review and a series of interviews. Thirty-one papers from the literature review were analysed, and 16 people from five different companies were interviewed.

Findings - The authors identified five different sources of resistance and three managerial approaches to dealing with them. The sources of resistance were based on (1) feelings of over-supervision, (2) unclear values, (3) feelings of inadequacy, (4) concerns about loss of power and jobs and (5) work overload. The three approaches to dealing with resistance are (1) communication, (2) participation and (3) training.

Originality/value - This work identifies the sources and strategies to deal with resistance to the use of Industry 4.0 technologies in the management of production disturbances. The managerial literature in this area is limited, and to the authors's knowledge, the specific sources for resistance and strategies to deal with that in this topic have not been systematically investigated before.
\end{abstract}

Keywords Resistance, Production disturbances, Managerial approaches

Paper type Research paper

\section{Introduction}

The introduction of Industry 4.0 (I4.0) technologies is expected to do for mental power what steam engine, electric power and automation did for muscle power (Snow et al, 2017). Production

(C) Adriana Ito, Torbjörn Ylipää, Per Gullander, Jon Bokrantz, Victor Centerholt and Anders Skoogh. Published by Emerald Publishing Limited. This article is published under the Creative Commons Attribution (CCBY 4.0) licence. Anyone may reproduce, distribute, translate and create derivative works of this article (for both commercial and non-commercial purposes), subject to full attribution to the original publication and authors. The full terms of this licence may be seen at http://creativecommons. org/licences/by/4.0/legalcode

This work has been conducted under the Sustainable Production Initiative and Production Area of Advance at Chalmers. The project was financed by VINNOVA, Energimyndigheten and Formas, in the Produktion2030 programme. The authors are thankful to the research team in the "D3H" project for their work. The support of all these bodies is greatly appreciated.
Production disturbance management

Received 9 December 2020 Revised 31 March 2021 17 June 2021

Accepted 23 June 2021 
JMTM 32,9

\section{6}

systems will change from isolated optimised cells to fully integrated and automated flows (Haseeb et al., 2019). Systems will be intelligent and transparent, with the interconnection of people, machines and devices (Hermann et al., 2016; Lee et al., 2015, 2017). Among the leading I4.0 technologies are smart sensors and devices, big data, data analytics, advanced robotics, Internet of Things, cloud computing, additive manufacturing, augmented reality, virtual reality and cyber-physical systems (Chen et al., 2018; Haseeb et al., 2019; Xu et al., 2018).

The use of different technologies will also affect how companies manage their production disturbances. Production disturbances are unwanted events that cause the production system not to perform as planned, such as machine failure or human error. To illustrate the size of the problem, almost half of the production capacity of manufacturing companies in Sweden is estimated to be compromised due to disturbances (Ylipää et al., 2017). However, with the implementation of I4.0 technologies, production disturbances will drastically reduce, and a worry-free system is even envisioned (Lee et al., 2015, 2017).

Nevertheless, companies are expected to face managerial challenges in implementing and using different technologies to handle disturbances. It is estimated that two-thirds of organisations' efforts to implement changes run into failure (Damschroder et al., 2009), and the leading reason for that has to do with human resistance (Kotter and Schlesinger, 2008; Pardo Del Val and Martínez Fuentes, 2003). Resistance slows down the implementation and introduces unexpected costs that may compromise the change process in the organisation (Pardo Del Val and Martínez Fuentes, 2003). In the case of the introduction of I4.0 technologies in disturbance management, resistance to the use of technology may hinder companies to achieve the goal of reducing disturbances' frequency. Resistance is regarded as a potential barrier to I4.0 realisation (Birkel et al., 2019; Horváth and Szabó, 2019). In addition, there is a research gap regarding the identification of sources of resistance and approaches to deal with that in I4.0 context, indicating the need of future research in this area as suggested by both Birkel et al. (2019) and Horváth and Szabó (2019).

To guarantee the proper implementation and use of I4.0 technologies and, consequently, full attainment of the benefits of production disturbance management, it is necessary to understand the sources of resistance and the different suitable approaches to deal with them. Therefore, this article aims to answer the following research questions:

$R Q 1$. What are the sources for resistance in the implementation and use of I4.0 technologies in the management of production disturbances?

$R Q 2$. What managerial approaches might companies use to deal with resistance in this context?

This paper is organised as follows. First, there is a presentation of the theoretical framework relating this work to previous publications. This is followed by a description of the methods used. The results are then presented regarding the causes of resistance and suitable approaches to dealing with them. A discussion is then presented, followed by the conclusions.

\section{Theoretical framework}

\subsection{Industry 4.0 emerging technologies}

Industry 4.0 technologies offer a new operating paradigm to industry. It allows for greater efficiency and productivity, leading to the creation, through digitalisation, of smart factories (Lasi et al., 2014; Thoben et al., 2017; Xu et al., 2018). I4.0 is designed based on the principles of interconnection, decentralisation of decisions, information transparency and technical assistance (Hermann et al., 2016). Machines, devices, sensors and people are interconnected through wireless communication technologies, providing very rapid interactions. All actors can share information, allowing greater transparency as to what is happening in the system. By following a common set of rules, the various actors can make decentralised decisions. 
Humans gain virtual and physical assistance in their tasks, while robots carry out activities that are unpleasant, exhausting or unsafe (Hermann et al., 2016).

Many benefits are anticipated when manufacturing companies adopt I4.0 technologies. These include a reduction in production costs, plus the enhancement of productivity, quality and safety (Moeuf et al., 2018; Müller et al., 2018; Zheng et al., 2020). Greater customisation of products may be achieved by creating flexible production systems (Lasi et al., 2014). Moreover, a reduction in the environmental impact of production systems is also anticipated, due to more efficient use of raw materials and energy (Müller et al., 2018).

Many technologies must be further improved if I4.0 is to find industrial applications. Among the leading technologies are: data analytics, big data, advanced robotics, the Internet of Things and people, cloud computing, additive manufacturing and augmented and virtual reality (Chen et al., 2018; Haseeb et al., 2019; Xu et al., 2018). For many technical challenges to the maturation of I4.0 technologies so that they can be introduced in industrial setting, it is natural that most research in the field focuses on the technical side.

However, research focussing on managerial aspects is also needed so that companies can successfully introduce these technologies into their production systems. Soft dimensions, such as organisational strategies, structure, culture and workforce should also be considered during the transition to the I4.0 era (Santos and Martinho, 2020).

\subsection{Production disturbances}

Production disturbances are unexpected and undesired events that cause a production system to not perform as planned. Equipment or software failures, media errors, waiting time for materials, subsequent stoppages in output flow from stations/machines, staff shortages, speed loss, scrap or quality problems, planning errors and adjustments are factors often classed as disturbances by manufacturing companies (Bokrantz et al., 2016a, b).

The occurrence of disturbances directly affects the efficiency and productivity of production systems since more time and natural resources are needed to produce the same item (Alsyouf, 2007). In other words, disturbances negatively affect production performance and impact companies' profitability. Reducing production disturbances contributes to safer and more reliable production systems (Toulouse, 2002) and is crucial in maintaining the competitiveness of manufacturing companies (Islam and Tedford, 2012).

With the rise of I4.0 technologies, disturbances such as machine failure, speed losses and planning errors are expected to reduce significantly. Intelligent actors (sensors, machines and devices) will be able to predict potential disturbances and reconfigure the system to prevent them from happening (Lee et al., 2017). In that sense, not only is the incidence of production disturbances expected to be affected by I4.0 technologies but also the way companies manage them.

The management of production disturbances refers to the actions taken to detect, diagnose, mitigate, analyse, predict and prevent disturbances. Manufacturing companies use different tools and methods to manage their production disturbances. The more common tools and methods are root cause analysis, fishbone diagram, failure mode and effect analysis and fault tree analysis (Bokrantz et al., 2016a, b).

The use of smart sensors and devices in production systems allows not only fast detection and mitigation of disturbances but also an extensive collection of data for use in further analysis, prediction and prevention (Reis and Gins, 2017). Real-time access to production system status is possible from anywhere via the Internet of Things and cloud technologies. Data analytics provides the means to generate insights into the causes of the disturbances and to support decision-making (Brundage et al., 2017). Virtual reality makes it possible to simulate "what-if" events in a safe platform and then determine preventive and corrective action. Introducing different technologies to the management of production disturbances builds a new standard; one which replaces the traditional pen-and-paper approach.
Production disturbance management 
JMTM 32,9

288

\subsection{Resistance}

Organisations implement change continuously. This is often necessary to bring about a competitive advantage and/or guarantee business survival. It is a response, not only to market pressure but also institutional pressure from regulatory agencies, the state, professions and general social expectations, among other things (Greenwood et al., 2011).

Even when a change seems to be "positive" or "rational", it involves uncertainty. This can cause emotional turmoil to those involved in the process (Bordia et al., 2004). A common response to uncertainty is human resistance; a means for individuals to try and guarantee stability and permanence of the status quo, by avoiding change (Pardo Del Val and Martínez Fuentes, 2003). Resistance introduces costs and delays to the change process that are difficult to anticipate (Pardo Del Val and Martínez Fuentes, 2003).

Kotter and Schlesinger (2008) suggest four different reasons for resistance: parochial selfinterest, misinterpretation/lack of trust, people's different assessments and low tolerance to change. Still, according to the authors, people tend to resist when they believe they will lose something they value; when they do not trust those involved in the change, when they do not understand the reasons behind the change and when they believe they cannot adapt to the new situation.

Nonetheless, resistance is not solely linked to a negative response to change. Some researchers suggest that resistance is also a way for an individual to communicate discomfort, leading perhaps to improvements in the process and content of the change (Pardo Del Val and Martínez Fuentes, 2003; Piderit, 2000). An effective strategy for dealing with resistance leads to organisational gains.

In discussing uncertainty and resistance in the change process, Bordia et al. (2004) and Wittig (2012) point out communication and employee participation in the decision process as efficient managerial approaches. These same strategies are also supported by Kotter and Schlesinger (2008), alongside training, negotiation and coercion. These different managerial approaches support a smoother implementation process of change within organisations towards employee acceptance.

On a user reaction spectrum, acceptance is at the opposite end to resistance (Wittig, 2012). In this work, acceptance is defined as the consistent and committed use of technology. Resistance and acceptance are interrelated and, in the implementation process, leaders struggle to tackle the former and promote the latter.

Resistance may be anticipated when implementing I4.0 technologies within production disturbance management. However, the sources of resistance and suitable managerial approaches to dealing with it have not so far been investigated in this context.

\section{Methods}

A qualitative approach was chosen for this research. The use of technologies to manage production disturbances is a fairly new phenomenon. In this case, therefore, it is appropriate to adopt a flexible and open approach to knowledge-building (Edmondson and Mcmanus, 2007).

To perform this research, two methods were chosen: a literature review and a multiplecase study. The combination of the methods allowed the comparison of results, leading to a better description of the sources and approaches to deal with resistance. With the literature review, investigation from a broader perspective was possible (Thomé et al., 2016), while the multiple-case studied provided a field for in-depth investigation (Stokes and Bergin, 2006).

The work began with the literature review. This method is suitable as it provides an overview of current research into a given issue (Snyder, 2019; Thomé et al., 2016; Webster and Watson, 2002). Furthermore, it provides the possibility of a broader interpretative context as it analyses multiple papers that adopt different research methods, data and settings (Mulrow, 
1994; Petticrew and Roberts, 2008). With the results of the literature review, preliminary insights could be reached, which were the starting point for the next step - a series of semistructured interviews with practitioners.

The series of semi-structured interviews were conducted with practitioners working in production disturbance management. This approach was chosen for several reasons. First, it implies the study of the phenomena in their natural setting, making it possible to construct knowledge from actual practices (Voss et al., 2002). Second, through interviews, it is possible to explore the facts in-depth (Stokes and Bergin, 2006). Third, a semi-structured interview is a versatile and flexible method, allowing the improvisation of follow-up questions. This yields interesting and unexpected data from participants' responses (Kallio et al., 2016; Myers and Newman, 2007).

The following subsections present the procedures for both the literature review and the interviews.

\subsection{Literature review}

The literature review was conducted according to the process suggested by (Seuring and Gold, 2012). First, the research questions were formulated, as presented in the Introduction section. The inclusion and exclusion criteria for selecting articles were then defined. The including criteria were: articles written in English, peer-reviewed conference and journal publications, empirical and theoretical articles, articles related to I4.0, to industrial applications and to resistance. If an article failed to attend one of those criteria, then it was excluded.

Scopus was selected as the database for the search due to its extensive content coverage. The search began with the keywords ("industr* 4.0" OR "smart manufacturing" OR "smart factory") AND ("resistance" OR "acceptance" OR "change management") AND ("disturbance" OR "failure" OR “incident” OR “downtime”)).

However, no relevant articles were found using these criteria. To broaden the search, keywords related to disturbances were excluded, for example ("disturbance" OR "failure" OR "incident" OR "downtime"). That allowed the collection of articles related to resistance in I4.0 from a general perspective; in other words, not only focused on disturbances. The second search revealed 93 articles. All abstracts were catalogued in a file and read. From those, 53 articles were selected for full reading, in case that they directly fulfilled the inclusion/ exclusion criteria, or if it was dubious if they fulfilled the criteria. After full reading, 31 articles were considered relevant to the purpose of this work.

Of the selected papers, $81 \%$ present empirical findings. The publication years range from 2016 to 2020. Each of the selected papers was examined, looking for content relating to resistance. The NVivo software was used. Different categories were then identified for the various sources of resistance and approaches to dealing with it.

\subsection{Interview with companies}

To select the interviewees, a search was made for manufacturing companies that apply technology in production disturbance management and software companies that develop solutions for the purpose of managing disturbances. Four manufacturing companies and one software company were selected for interview. A brief description of them is presented in Table 1 .

The manufacturing companies use the same software for registration and control of production disturbances. This software is provided by the software company that also took part in this research, which created the opportunity for the authors to investigate resistance from the solution provider's perspective (software company) and from the manufacturing companies' perspective.

The software enables automatic disturbance detection and registration. However, operators have to identify and record (referred also as code in this text) the cause of the
Production disturbance management 
JMTM 32,9

290

disturbance in the software. Furthermore, automatic reports may be generated which show various performance measurements, such as frequency and duration of the disturbances and their causes, related shifts/operators, machines and products.

Semi-structured interviews were carried out with representatives of the manufacturing companies directly involved in handling production disturbances. These followed an interview guide as suggested by Kallio et al. (2016), which was developed and discussed beforehand among the authors of this paper. The focus of the interviews was to understand how I4.0 technologies are used in disturbance management and the challenges regarding the use of the software for the registration/control of disturbances. In addition, the interviews concentrated on possible sources of resistance to software use. Finally, the different approaches used by the companies to tackling resistance were also explored.

The interviews started by asking the interviewees to describe the process of managing disturbances in the companies. Focus was given to the different involved roles and the supporting technologies. Then, the interviewees were asked to describe specifically the process of reporting disturbances among operators, focussing on the challenges regarding resistance and providing examples of when and how they perceived resistance among the operators. Further, the interviewees were asked to describe the different consequences of resistance in their companies, as well as describe and provide examples of how they managed situations where resistance was present. Finally, the interviewees were asked if they perceived that the technology used to report disturbances provided any benefits to the operators, as well as if they used any strategies to enhance technology acceptance.

In the case of the software company, the interviews focused on understanding the company's perception of how their customers deal with resistance to the use of the software.

The interviews with the manufacturing companies were conducted in Swedish and at least one native-speaker researcher was present. The interview with the software company was conducted in English. A total of 16 people were interviewed, and their roles in their companies are shown in Table 2.

The interviews were recorded and transcribed. Their content was then analysed using NVivo. Deductive coding was used for the analysis, based on the various categories defined in the literature review stage. The transcripts were examined line-by-line. Supplementary,

Table 1.

Description of companies

\begin{tabular}{llc}
\hline Company & Description & Employees in plant/office \\
\hline 1 & Cider and beer brewery - batch production & 460 \\
2 & Tool steel manufacturer - job shop production & 900 \\
3 & Polymeric component manufacturer - job shop production & 114 \\
4 & Metal profile manufacturer - job shop production & 25 \\
5 & Software development for industrial application & 16
\end{tabular}

\begin{tabular}{lcl}
\hline Company & $\begin{array}{c}\text { Number of people } \\
\text { interviewed }\end{array}$ & Positions in company \\
\hline 1 & 6 & $\begin{array}{l}\text { Plant manager, maintenance manager, line supervisors (3) and } \\
\text { continuous improvement group coordinator } \\
\text { Technical engineer, maintenance leader and production leader }\end{array}$ \\
2 & 3 & $\begin{array}{l}\text { Plant manager, tool manager and technical engineer } \\
\text { Production supervisor, maintenance supervisor and maintenance } \\
\text { engineer } \\
4\end{array}$ \\
5 & 3 & Technical manager
\end{tabular}

Table 2.

Interviewee profiles 
secondary data were also collected and analysed, such as the companies' internal documents and annual reports.

To increase the robustness of the data and the analyses, the results were presented to six of the interviewees for the purpose of member checking (Birt et al., 2016). Their comments were incorporated into the work.

\section{Findings}

Subsections 4.1 and 4.2 present the findings regarding sources of resistance and the approaches to dealing when managing production disturbances. These findings were combined with the presentation of results from the literature review and interviews.

\subsection{Sources of resistance}

Table 3 presents the distribution of selected papers during the literature review, regarding the various sources of resistance, plus selected statements from the practitioner interviews. The five different sources identified are detailed in subsections 4.1.1 to 4.1.5.

4.1.1 Feeling of over-supervision. The extensive collection of data from sensors, machines, devices and people creates the means to achieve transparency of information in production systems. Access to real-time information is possible, not only for the status of the machines but also that of employees (Pradhan and Agwa-Ejon, 2018). Different technologies contribute

\begin{tabular}{|c|c|}
\hline $\begin{array}{l}\text { Source of } \\
\text { resistance }\end{array}$ & Related articles \\
\hline $\begin{array}{l}\text { Feelings of over- } \\
\text { supervision }\end{array}$ & $\begin{array}{l}\text { Aromaa et al. (2019), Birkel et al. (2019), } \\
\text { Horvath et al. (2018), Horváth and Szabó } \\
\text { (2019), Kaasinen et al. (2019), Klumpp et al. } \\
\text { (2019), Merhar et al. (2019), Mora Sanchez } \\
\text { (2019), Pradhan and Agwa-Ejon (2018) and } \\
\text { Zimmermann et al. (2019) }\end{array}$ \\
\hline Unclear values & $\begin{array}{l}\text { Bag et al. (2018), Birkel et al. (2019), Bruno } \\
\text { et al. (2019), Hahm (2018), Le Grand and } \\
\text { Deneckere (2019) and Merhar et al. (2019) }\end{array}$ \\
\hline $\begin{array}{l}\text { Feelings of } \\
\text { inadequacy }\end{array}$ & $\begin{array}{l}\text { Bag et al. (2018), Birkel et al. (2019), Bruno } \\
\text { et al. (2019), Chei et al. (2019), Daling et al. } \\
\text { (2020), Eimontaite et al. (2019), Greinke } \\
\text { et al. (2016), Hahm (2018), Horváth and } \\
\text { Szabó (2019), Klumpp et al. (2019), Loch } \\
\text { et al. (2016), Merhar et al. (2019), Pejic-Bach } \\
\text { et al. (2020), Whysall et al. (2019) and } \\
\text { Zimmermann et al. (2019) }\end{array}$ \\
\hline $\begin{array}{l}\text { Concerns about } \\
\text { job and power loss }\end{array}$ & $\begin{array}{l}\text { Birkel et al. (2019), Eimontaite et al. (2019), } \\
\text { Hahm (2018), Horvath et al. (2018), Horváth } \\
\text { and Szabó (2019), Klumpp et al. (2019), Le } \\
\text { Grand and Deneckere (2019), Mora } \\
\text { Sanchez (2019), Pradhan and Agwa-Ejon } \\
\text { (2018) and Xing et al. (2019) }\end{array}$ \\
\hline Work overload & Birkel et al. (2019) \\
\hline
\end{tabular}

Sample statement from interviews

"The breaks [referring to the operators" pauses to rest] became shorter because people feel over-monitored"

"There is no 'why'. But if you do not understand why you're using the technology, you're not going to use it" "Sometimes there is a dislike of doing something different because people have always done things a certain way. It can be troublesome with the new technology [referring to learning how to use the new software]"

-Not identified as a source of resistance-

"People cannot be in two places at the same time. Sometimes there is a problem in one machine and the operator is trying to solve the problem... And then another problem comes. It is very difficult to find the actual root cause"
Production disturbance management

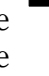


JMTM 32,9

292

to this scenario, such as the Internet of Things, cloud technologies, smart sensors and devices (Birkel et al., 2019; Zimmermann et al., 2019). Managers and supervisors can track where employees are and check their activities; even employee health parameters can be monitored (Horvath et al., 2018; Horváth and Szabó, 2019).

Extensive data collection allows deep analysis of employee performance, and managers are willing to use it (Horváth and Szabó, 2019). On the employee side, Merhar et al. (2019) show that while some employees are indifferent to how their data is being used, others fear managers using it in ways that go against their interests.

In this regard, privacy issues are identified as a risk factor with I4.0 (Mora Sanchez, 2019; Pradhan and Agwa-Ejon, 2018). Revealing the mistakes, current status and health data of employees may go against their interests and lead to resistance to the use of technology in work environment (Kaasinen et al., 2019; Zimmermann et al., 2019). Some employees might be reluctant to share personally identifiable information (Aromaa et al., 2019). Resistance may also result when the constant surveillance created by technology causes people to perceive a lack of freedom and autonomy (Klumpp et al., 2019).

Consistent with the findings of the literature review, this work's empirical findings suggest that operators have a feeling of constant supervision regarding the use of technology to manage production disturbances:

They [the operators] think we want to check what they're doing. There is mistrust that the system is being used to check people and not the machines.

The operators are meant to report when a machine stops due to their breaks/pauses to rest. Some interviewees suggested that, due to feelings of over-supervision, use of the software affected the length of operator breaks - they became shorter since the operators felt monitored.

Another challenge identified was that the operators sometimes fear that the collected data may be used against them. In certain situations, the interviewees perceived that inaccurate information might be deliberately supplied by operators to avoid a reprimand:

We have a code [referring to the choice of the disturbance's cause in the software] called "lack of people". This is meant to be used when people are sick, for example, and there is no substitute. [. . .] If there's a machine without an operator, sometimes the operator codes it as a lack of people, even though we've clarified that this is not the case.

In addition, the interviewees also mentioned that operators dislike it when the data points out their mistakes.

People want to avoid this feeling that they've done something wrong.

4.1.2 Unclear value. Resistance may emerge among employees when they do not understand why a technology is being adopted or used in the organisation (Le Grand and Deneckere, 2019). In other words, resistance may arise when the value of using technology is unclear to the employees (Birkel et al., 2019).

Once they fully understand its benefits, employees tend to have a positive attitude towards the adoption and use of technology (Bag et al., 2018; Hahm, 2018). Regarding the adoption of augmented reality tools compared to the paper-based practice for detecting anomalies, Bruno et al. (2019) also identify that practitioners who see a high value in using this technology tend to consent to its use.

In the change process, it is common for the decision to adopt a new technology to be made by the manager and not the end-user. The value of using the technology may be clear to the manager but the same might not apply to the employee. The level of information an employee can access affects their acceptance of using the technology. However, it is common for employees to not feel well-informed of the reasons for the change and its underlying value 
(Merhar et al., 2019). In addition, while the use of certain technologies might have a direct impact at organisational level, this may not be easily perceived at the operational level. At the organisational level, digital technologies might improve such things as planning, maintenance, quality operations and decision-making (Le Grand and Deneckere, 2019) but not necessarily bring any direct value to employee tasks.

Consistent with the reviewed literature, the empirical findings of this work corroborate that unclear value is also a potential source of resistance to using technology in production disturbance management. The interviewees pointed out that operators should know what is being done at organisational level with the data collected on the shop floor. If operators do not understand the exact purpose of using technology in the organisation, they might become unmotivated.

It is quite natural that resistance appears when the person does not use the data, and it is just a task to feed the data in.

Moreover, the interviewees also stated that operators should be made aware of how the correct use of technology impacts operational performance. Operators tend to show a more positive attitude towards using technology when they can see a tangible result.

As an operator, I think you want to see what the management team is doing with the data. . That they're actually looking into the data and making their decisions based on it. ...]... if you code [referring to manually choosing the disturbance's cause in the software] and you see that $70 \%$ of our stops are because we do not have a hammer and they do not provide a hammer [figurative speech]. . . You might think, "why are not listening to what I'm saying?"

The interviewees also found that new functions could be added to the technology to increase its usefulness to an operator in carrying out their own tasks. In the case of dealing with a production disturbance, this might be achieved by, say, using the suggestion function to search for solutions in past data. This function can support operators in their duties.

It would be nice if operators could have a function to search for solutions. A solution button.

4.1.3 Feeling of inadequacy. The changes brought about by the introduction of I4.0 technologies demand adaptation from the employees' side. New technical and soft skills are required, such as IT-related knowledge and problem-solving capacity (Birkel et al., 2019; Pejic-Bach et al., 2020; Whysall et al., 2019). Employees may fear not having the necessary abilities to handle and adapt to using new technologies (Horváth and Szabó, 2019). Stress and anxiety may arise, especially if there is pressure on the employee to learn new tasks or acquire new knowledge in a short time (Birkel et al., 2019). This may lead to feelings of inadequacy and frustration (Daling et al., 2020). People tend to resist when they fear not adapting to, or developing, expected new behaviours brought about by new technology. Individuals must feel confident in their abilities if they are to accept and use I4.0 technologies (Eimontaite et al., 2019; Hahm, 2018; Klumpp et al., 2019).

Feelings of inadequacy may also emerge when an employee finds using the new technology too complicated. Employees tend to be positive about adopting I4.0 technologies, if they are easy to apply to the work environment (Bag et al., 2018; Chei et al., 2019; Zimmermann et al., 2019). When people are intimidated, there is a negative effect on their intention to use the technology, leading to resistance (Bag et al., 2018). Moreover, usability should be incorporated into technological design. This prevents resistance and promotes acceptance of wearable technologies, such as augmented reality or smart jackets (Bruno et al., 2019; Greinke et al., 2016; Loch et al., 2016; Merhar et al., 2019).

The empirical findings of this work are consistent with the findings in the literature. During the interviews, it was mentioned that some operators might perceive using new technology as difficult, making them less willing to use it:

Production disturbance management 
JMTM 32,9

Some operators, especially the older ones, do not like the touch screen; they do not like the new system. It's too complicated. . . they prefer pen and paper.

To create greater operator engagement, companies consider that technology should be as simple as possible. If too much information is presented confusion may result, compromising the performance of the task. Furthermore, the interviewed practitioners recognise the need for proper knowledge regarding the production process so the operators may use the technology accordingly:

Sometimes people just do not really know what to code [referring to manually choosing the disturbance's cause in the software]. It's not crystal clear. People just do not know what code to use, so they do not do it.

4.1.4 Concern about job and power loss. According to Birkel et al. (2019), the risk of major unemployment is one of the main social challenges of I4.0. It is anticipated that various tasks currently performed by humans will be automated (Birkel et al., 2019; Mora Sanchez, 2019). To enhance safety robots might replace humans in, say, extreme work environments and physically demanding activities (Mora Sanchez, 2019). Other strong candidates for automation include repetitive tasks as this allows higher quality and production stability (Birkel et al., 2019; Pradhan and Agwa-Ejon, 2018). Various publications refer to employee fears that I4.0 technologies will take away their jobs (Eimontaite et al., 2019; Hahm, 2018; Horváth and Szabó, 2019; Klumpp et al., 2019; Le Grand and Deneckere, 2019; Mora Sanchez, 2019; Pradhan and Agwa-Ejon, 2018).

Physical and repetitive tasks are unlikely to be the only things impacted by the introduction of I4.0 technologies. Mentally demanding activities, such as maintenance and production planning, product quality assurance and stock control may also be replaced via industrial big data and artificial intelligence (Birkel et al., 2019; Xing et al., 2019). It is anticipated that decision-making tasks currently undertaken by humans will be largely decentralised to various actors in the system, such as devices and machines (Xing et al., 2019). People might feel excluded from day-to-day decisions in this scenario, as data will be used to handle them automatically (Klumpp et al., 2019). A power shift within organisations, created by the use of the new technologies, may lead to resistance (Birkel et al., 2019). Mid-level managers are highlighted as possible agents of resistance, due to the threat to their power (Birkel et al., 2019; Horvath et al., 2018).

In the interviews conducted for this study, no interviewees mentioned fear of losing their jobs or influence as a source of resistance. One explanation might be that the specific technology used within companies to manage production disturbances may not be perceived as a threat to operator jobs or power. While using the technology, the operator is still central to the task, particularly when assessing the cause of disturbances. Consequently, in this specific context, technology does not lead to fear of replacement or loss of power. In addition, the companies interviewed for this work are located in Sweden. The Swedish social security system is robust, so workers likely feel safer regarding their jobs.

However, the authors believe that fear of losing jobs and power may produce resistance to using other types of technology and/or to its use in other countries, as suggested in the literature reviewed.

4.1.5 Work overload. A potential risk resulting from the introduction of I4.0 technologies is employee work overload (Birkel et al., 2019). Additional tasks may accompany the use of I4.0 technologies. Moreover, new demands may lead to more responsibility and result in a perceived heavier burden on the operator. The new skills and competencies that employees would be expected to learn might also trigger feelings of being overwhelmed.

Resistance to the use of the technology may also come as a consequence of employees having too much to do and limited time to do it properly. Due to lack of time, employees might 
feel forced to prioritise certain tasks. Thus, they might not judge the proper use of the technology to be urgent and deprioritise it.

The implementation of technology in the companies where interviews were conducted led to transformations of the tasks done by the operators. Before implementation, only major disturbances were recorded and had their causes investigated. After implementation, all disturbances were automatically recorded. Operators must investigate nearly all disturbances and determine their causes. Thus, implementation of the technology imposed an amplified workload on operators. The interviewees mentioned how some operators felt that sometimes they just do not have enough time to do their tasks properly. In those cases, they might prioritise their tasks according to their assessment of what is more relevant and deprioritise using the technology properly.

Time pressure is also a problem. Sometimes you report things just for the sake of it.

A lot of time is spent looking for what the problem actually is.

Work overload is barely regarded as an issue when implementing and using I4.0 technologies; only one of the reviewed papers mentioned it. Paradoxically, the authors' empirical findings demonstrate that the changed tasks brought about by introducing various technologies might lead to work overload.

\subsection{Approaches to dealing with resistance}

Table 4 contains the distribution of papers in the literature review regarding different approaches to dealing with resistance, plus excerpts from the interviews. Explanations are given in the subsequent subsections.

4.2.1 Communication. Communication plays a critical role in digital transformation (Romero and Flores, 2019). By communicating the intended outcomes, it is possible to create a positive mindset among employees regarding the benefits of the technology (Bag et al., 2018; Romero and Flores, 2019). Then employees can understand how and why a specific I4.0

\begin{tabular}{ll}
\hline Approaches & Related articles \\
\hline Communication & $\begin{array}{l}\text { Bag } \text { et al. (2018), Birkel } \text { et al. (2019), Hahm } \\
\text { (2018), Helming } \text { et al. (2019), Le Grand and }\end{array}$ \\
& $\begin{array}{l}\text { Deneckere (2019) and Romero and Flores } \\
\text { (2019) }\end{array}$ \\
& Aromaa et al. (2019), Bag et al. (2018), Birkel \\
Training & et al. (2019), Daling et al. (2020), Gaspar \\
& (2018), Hahm (2018), Hakim and Putriandita \\
& (2018), Helming et al. (2019), Horváth and \\
& Szabó (2019), Kumar et al. (2019), Le Grand \\
& and Deneckere (2019), Loch et al. (2016), \\
& Merhar et al. (2019), Mora Sanchez (2019), \\
& Ochs and Riemann (2016), Pejic-Bach et al. \\
& (2020), Pradhan and Agwa-Ejon (2018), \\
& Romero and Flores (2019), Schallock et al. \\
& (2018), Schuldt and Friedemann (2017), \\
& $\begin{array}{l}\text { Schumacher } \text { et al. (2016), Whysall } \text { et al. } \\
\text { (2019) and Xing } \text { et al. (2019) }\end{array}$ \\
& Kaasinen et al. (2019), Le Grand and \\
& Deneckere (2019) and Merhar et al. (2019)
\end{tabular}

"Difficult code names [referring to the choice of the disturbance's cause]. I think it should always be the operators who participate in choosing them"
Sample statement

"It is important to give more feedback about what we do with the data"

"We usually have a honeymoon month so everyone can learn about the system and get away from the fear of 'we cannot make a mistake'. We do not check, we just learn from the data"
Production disturbance management

295
Table 4.

Approaches to dealing with resistance 
JMTM 32,9

296

technology is being adopted and implemented in the organisation. Hahm (2018) suggests that managers should present employees with evidence of the positive outcomes of introducing various technologies.

The presentation of a clear strategy for implementing and using the technologies is also needed to handle resistance among employees (Birkel et al., 2019). How the implementation is expected to happen and its side consequences should be clearly informed to the employees, even if there are drawbacks. An unclear situation with rumours swirling around the change can have a strong negative impact on the process and should therefore be avoided (Le Grand and Deneckere, 2019). For that reason, it is also essential that managers should not leave any questions unanswered (Le Grand and Deneckere, 2019).

In this scenario, employees should also be allowed to express their concerns. Le Grand and Deneckere (2019) observed that employees who have undergone a change would like to have been asked about their opinions and concerns before and during the change. Managers may use communication to encourage employees, making them feel more confident (Hahm, 2018).

Helming et al. (2019) highlight the need for reflection regarding how communication is conducted. Face-to-face communication, for example, might have different impacts than, say, digital communication.

Regarding communication as an essential approach to dealing with resistance, there is agreement between the literature and the empirical findings of this work. The interviewees pointed out that communication is necessary to show the value of the technology to the operators and clarify the intended outcomes of using it. In addition, the interviewees also feel that constant feedback is necessary so that operators know what should be improved.

We know it's very important to give feedback. We can give feedback about how the problem has actually been solved and which actions were taken.

People need feedback about what they are supposed to feed into the software.

4.2.2 Training. Training is regarded as a key success factor for I4.0 adoption (Hakim and Putriandita, 2018). Several authors recognise the need to train the workforce so that it develops and improves the required skills and competences (Bag et al., 2018; Birkel et al., 2019; Hakim and Putriandita, 2018; Helming et al., 2019; Horváth and Szabó, 2019; Kumar et al., 2019; Le Grand and Deneckere, 2019; Merhar et al., 2019; Mora Sanchez, 2019; Ochs and Riemann, 2016; Romero and Flores, 2019; Whysall et al., 2019). "Competence management" is considered one of the pillars of I4.0 readiness (Schumacher et al., 2016).

With the introduction of I4.0 technologies, new technical and soft skills will be required (Pejic-Bach et al., 2020; Schallock et al., 2018; Whysall et al., 2019). Technical skills include data analysis, data modelling, knowledge about cyber-physical systems, the Internet of Things and robotised production, among others (Kumar et al., 2019; Pejic-Bach et al., 2020; Pradhan and Agwa-Ejon, 2018; Xing et al., 2019). Soft skills include the capacity of problem-solving, teamwork, proposing and implementing changes, adaptation and collaboration (Pejic-Bach et al., 2020; Schallock et al., 2018).

Training provides the means for employees to update their knowledge and learn how to use a new technology (Hahm, 2018). The training sessions allow the value of the new technologies to be illustrated by presenting all their features and potential uses (Bag et al., 2018). Furthermore, it allows the employees' questions and concerns to be addressed (Gaspar, 2018).

Successful I4.0 training requires efforts not just from the industrial sector but also from an academic perspective; research institutes and universities for example (Kumar et al., 2019; Pradhan and Agwa-Ejon, 2018). Manufacturing companies should cooperate with universities and other educational organisations to develop educational programmes (Horváth and Szabó, 2019). 
Apart from upgrading employees' skills, the management of I4.0 also requires specific training (Whysall et al., 2019). Using new technologies brings about shifts in the relationship between managers and employees. Helming et al. (2019) propose a specific course for leadership 4.0, allowing managers to develop the necessary skills for this new setting.

Different forms of training are proposed, to accelerate the learning curve of the working force. The use of learning factories allows employees to learn from a familiar scenario when trying out new technologies (Schallock et al., 2018). Another training method is gamification; using games in the learning process creates a safe place for questions and mistakes (Schuldt and Friedemann, 2017).

The use of I4.0 technologies as training media is also possible. For example, various researchers suggest using augmented reality and simulation in training sessions (Aromaa et al., 2019; Daling et al., 2020; Loch et al., 2016).

Among the manufacturing companies interviewed for this work, brief training was carried out in the early stages of implementation, using the software to record disturbances. The training is intended to provide a period in which operators can try out the different features of the technology and become confident in its use:

We usually have a honeymoon month so everyone can learn about the system and get away from the fear of "we cannot make a mistake". We do not check, we just learn from the data.

However, once the technology was implemented, a new requirement emerged regarding training. Using the technology in itself was simple but doing so required a deeper understanding of the process, to determine the cause of all the disturbances. This new requirement was not anticipated, so a new training in root cause analysis became necessary.

We now have a root cause analysis course. We will improve.

Consistent with the performed literature review, the authors' empirical findings also reveal a need for training as a strategy for dealing with resistance. However, the empirical findings suggest that particular attention should be paid to those skills/knowledge which may not necessarily refer to a specific use of the technology but to the consequences of that use.

4.2.3 Participation. To enhance employees' commitment and engagement in the use of a new technology, participation should be promoted. Through participation, people may understand the fundamental principles upon which technologies were developed. The value of the technology's use becomes clearer as its intended outcome (Merhar et al., 2019).

When participating in the development and implementation process, employees also have the opportunity to influence the features of the technology to better fit their needs and limitations. This promotes a sense of ownership (Le Grand and Deneckere, 2019). The great majority of industrial practitioners would be more inclined to use a technology that they had either designed or been consulted about during the implementation process (Kaasinen et al., 2019; Le Grand and Deneckere, 2019).

Participation may be promoted at different stages of the change; the decision to adopt, development of the technology, implementation or even updating of the technology. The scope of employee participation may also vary. In some circumstances, employees might only be consulted, whereas in others they might be actively engaged in decisions regarding new technology.

In the companies interviewed, participation is promoted in the choice of the codes used by operators to indicate the reasons for production disturbances. Operators may choose a name that is more intuitive to them, even though other departments in the company might use different designations.

Difficult code names [referring to the choice of the disturbance's cause in the monitoring software]. I think it should always be the operators who participate in choosing them.
Production disturbance management 
JMTM 32,9

However, the empirical findings in this work suggested that this approach is still very limited in practice. The authors believe that, with more extensive encouragement to participate, companies may benefit from reduced levels of resistance. This may be promoted in different stages of technological implementation and use.

\section{Discussion}

This study aimed to investigate the sources of resistance to the use of I4.0 technologies in the context of production disturbance management, along with suitable managerial approaches to deal with it. To this end, a literature review and a series of practitioner interviews were conducted. The results highlight five different sources of resistance: feelings of oversupervision, unclear values, feelings of inadequacy and concerns about job/power loss and work overload. In addition, the authors identified three approaches to deal with resistance in this context: communication, participation and training.

Overall, the findings of this study are aligned with general literature regarding resistance. As highlighted by Kotter and Schlesinger (2008) and Pardo Del Val and Martínez Fuentes (2003), resistance may be anticipated when organisations introduce some kind of change. Comparing with current literature, the authors' findings indicate the same to be the case in disturbance management. Furthermore, the identified approaches to handle resistance in this context are consistent with Bordia et al. (2004), Kotter and Schlesinger (2008) and Wittig (2012).

Regarding literature about disturbance management, this research adds to current knowledge. Previous studies have identified the current situation and challenges and proposed solutions for improving production disturbance management (Bokrantz et al., 2016a, b; Islam and Tedford, 2012). In addition, Brundage et al. (2017) and Reis and Gins (2017) have presented technological solutions that can be applied in the area. However, the literature and the body of knowledge are still limited. Specifically, how resistance is expected to emerge with technological use, and the different approaches to deal with it have not been previously studied in this context.

\subsection{Theoretical contributions}

This study makes several theoretical contributions. First, it clarifies and describes why resistance to the use of I.40 technologies is likely to emerge in the context of disturbance management. This is achieved by identifying five conceptual sources of resistance (feelings of over-supervision, unclear values, feelings of inadequacy and concerns about job/power loss and work overload). When those sources are present, resistance is likely to emerge. Second, it also identifies three suitable managerial approaches for dealing with resistance (communication, participation and training). By using these approaches, the sources of resistance can be mitigated, thereby increasing the likelihood of successful implementation and use of I4.0 technologies for managing disturbances. In essence, the theoretical implications of this study are improving construct validity and scope as well as explanatory and predictive adequacy of resistance theory, specifically in the context of disturbance management.

\subsection{Practical contributions}

The study also makes practical contributions. The introduction of I4.0 technologies has the potential to drastically improve disturbance management. However, to effectively introduce I4.0 technologies, companies should overcome resistance among employees. Therefore, from a practitioner perspective, the main contribution of this research is the identification and description of the sources of resistance and managerial approaches. Firstly, to be successful 
with introducing I4.0 technologies in disturbance management, managers need to understand the different sources of resistance to know what to tackle. Secondly, managers also need to understand how to tackle the sources of resistance; in other words, the suitable managerial approaches. Ultimately, this will help manufacturing companies exploit the benefits of I4.0 technologies in disturbance management.

\section{Conclusions}

This study contributes theoretically by identifying different sources of resistance as well as different approaches for dealing with them, specifically within the context of using I4.0 technologies to manage production disturbances. Five different sources of resistance were identified: feelings of over-supervision, unclear values, feelings of inadequacy and concerns about job/power loss and work overload. In addition, three approaches to deal with resistance were identified: communication, participation and training.

Regarding future work, the authors suggest to empirically test the theoretical propositions put forward by the study. There should be a specific hypothesis formulation for each of the proposed concepts and relationships, covering both the identified sources of resistance and the managerial approaches. In addition, future research can focus on determining if certain managerial approaches are particularly effective for dealing with a specific source of resistance. Furthermore, the authors suggest future work to focus on the human resource perspective, providing specific guidelines for how human resource managers can support production managers in dealing with resistance.

Finally, this study contributes to practice by supporting practitioners in better understanding the main sources of resistance and the most suitable approaches to overcoming it, thereby increasing the likelihood of successful implementation and use of I4.0 technologies for managing disturbances.

\section{References}

Alsyouf, I. (2007), "The role of maintenance in improving companies' productivity and profitability", International Journal of Production Economics, Vol. 105 No. 1, pp. 70-78, doi: 10.1016/j.ijpe.2004. 06.057 .

Aromaa, S., Liinasuo, M., Kaasinen, E., Bojko, M., Schmalfuß, F., Apostolakis, K.C., Zarpalas, D., Daras, P., Özturk, C. and Boubekeuer, M. (2019), "User evaluation of Industry 4.0 concepts for worker engagement Susanna”, International Conference on Human Systems Engineering and Design, Vol. 1, pp. 215-220, doi: 10.1007/978-3-030-02053-8.

Bag, S., Telukdarie, A. and Africa, S. (2018), "Industry 4.0 tool application: integration of TAM and TTF model perspective", International Conference on Industrial Engineering and Operations Management, pp. 2169-2174.

Birkel, H.S., Veile, J.W., Müller, J.M., Hartmann, E. and Voigt, K.I. (2019), "Development of a risk framework for Industry 4.0 in the context of sustainability for established manufacturers", Sustainability, Vol. 11 No. 2, pp. 1-27, doi: 10.3390/su11020384.

Birt, L., Scott, S., Cavers, D., Campbell, C. and Walter, F. (2016), "Member checking: a tool to enhance trustworthiness or merely a nod to validation?", Qualitative Health Research, Vol. 26 No. 13, pp. 1802-1811, doi: 10.1177/1049732316654870.

Bokrantz, J., Skoogh, A. and Ylipää, T. (2016a), "The use of engineering tools and methods in maintenance organisations: mapping the current state in the manufacturing industry", Procedia CIRP, Vol. 57, pp. 556-561, doi: 10.1016/j.procir.2016.11.096.

Bokrantz, J., Skoogh, A., Ylipää, T. and Stahre, J. (2016b), "Handling of production disturbances in the manufacturing industry", Journal of Manufacturing Technology Management, Vol. 27 No. 8, pp. 1054-1075, doi: 10.1108/JMTM-02-2016-0023. 
JMTM 32,9
Bordia, P., Hobman, E., Jones, E., Gallois, C. and Callan, V.J. (2004), "Uncertainty during organizational change: types, consequences, and management strategies", Journal of Business and Psychology, Vol. 18 No. 4, pp. 507-532, doi: 10.1023/B:JOBU.0000028449.99127.f7.

Brundage, M.P., Kulvantunyou, B., Ademujimi, T. and Rakshith, B. (2017), "Smart manufacturing through a framework for a knowledge-based diagnosis system”, 12th International Manufacturing Science and Engineering Conference, MSEC 2017, 3(June), doi: 10.1115/MSEC2017-2937.

Bruno, F., Barbieri, L., Marino, E., Muzzupappa, M., D’Oriano, L. and Colacino, B. (2019), "An augmented reality tool to detect and annotate design variations in an Industry 4.0 approach", International Journal of Advanced Manufacturing Technology, Vol. 105 Nos 1-4, pp. 875-887, doi: 10.1007/s00170-019-04254-4.

Chei, S.Y., You, Y.Y., Song, K.Y., Kim, J.S. and Cho, M.S. (2019), "Effects of manufacturing and nonmanufacturing occupations on smart manufacturing technology acceptance. UTAUT2 model perspective", International Journal of Innovative Technology and Exploring Engineering, Vol. 8 No. 8, pp. 65-70.

Chen, B., Wan, J., Shu, L., Li, P., Mukherjee, M. and Yin, B. (2018), "Smart factory of industry 4.0: key technologies, application case, and challenges”, IEEE Access, Vol. 6, pp. 6505-6519, doi: 10.1109/ ACCESS.2017.2783682.

Daling, L., Abdelrazeq, A., Sauerborn, C. and Hees, F. (2020), “A comparative study of augmented reality assistant tools in assembly", International Conference on Applied Human Factors and Ergonomics, Vol. 972, pp. 662-671, doi: 10.1007/978-3-030-19135-1.

Damschroder, L.J., Aron, D.C., Keith, R.E., Kirsh, S.R., Alexander, J.A. and Lowery, J.C. (2009), "Fostering implementation of health services research findings into practice: a consolidated framework for advancing implementation science", Implementation Science, Vol. 4 No. 1, pp. 1-15, doi: 10.1186/1748-5908-4-50.

Edmondson, A.C. and Mcmanus, S.E. (2007), "Methodological fit in management field research", Academy of Management Review, Vol. 32 No. 4, pp. 1155-1179, doi: 10.5465/AMR.2007.26586086.

Eimontaite, I., Gwilt, I., Cameron, D., Aitken, J.M., Rolph, J., Mokaram, S. and Law, J. (2019), "Language-free graphical signage improves human performance and reduces anxiety when working collaboratively with robots", International Journal of Advanced Manufacturing Technology, Vol. 100 Nos 1-4, pp. 55-73, doi: 10.1007/s00170-018-2625-2.

Gaspar, D. (2018), "Organizational value creation by IT in Industry 4.0 domonkos", IFIP Working Conference on The Practice of Enterprise Modeling, Vol. 3, March 2019, pp. 257-273, doi: 10.1007/ 978-3-030-02302-7.

Greenwood, R., Raynard, M., Kodeih, F., Micelotta, E.R. and Lounsbury, M. (2011), "Institutional complexity and organizational responses", Academy of Management Annals, Vol. 5 No. 1, pp. 317-371, doi: 10.1080/19416520.2011.590299.

Greinke, B., Guetl, N., Wittmann, D., Pflug, C., Schubert, J., Helmut, V., Bitzer, H.W., Bredies, K. and Joost, G. (2016), "Interactive workwear: smart maintenance jacket", Proceedings of the 2016 ACM International Joint Conference on Pervasive and Ubiquitous Computing, pp. 470-475, doi: 10.1145/2968219.2971346.

Hahm, S. (2018), "Attitudes and performance of workers preparing for the fourth industrial revolution", KSII Transactions on Internet and Information Systems, Vol. 12 No. 8, pp. 4038-4056, doi: 10.3837/tiis.2018.08.027.

Hakim, I.M. and Putriandita, A. (2018), "Designing implementation strategy for internet of things (IoT) on logistic transportation sector in Indonesia”, ACM International Conference Proceeding Series, pp. 23-28, doi: $10.1145 / 3288155.3288165$.

Haseeb, M., Hussain, H.I., Ślusarczyk, B. and Jermsittiparsert, K. (2019), "Industry 4.0: a solution towards technology challenges of sustainable business performance", Social Sciences, Vol. 8 No. 5, pp. 2-24.

Helming, S., Ungermann, F., Hierath, N., Stricker, N. and Lanza, G. (2019), "Development of a training concept for leadership 4.0 in production environments", 9th Conference on Learning Factories, Vol. 31, pp. 38-44, doi: 10.1016/j.promfg.2019.03.007. 
Hermann, M., Pentek, T. and Otto, B. (2016), "Design principles for Industry 4.0 scenarios", Proceedings of the Annual Hawaii International Conference on System Sciences, 2016-March, pp. 3928-3937, doi: 10.1109/HICSS.2016.488.

Horváth, D. and Szabó, R.Z. (2019), "Driving forces and barriers of industry 4.0: do multinational and small and medium-sized companies have equal opportunities?", Technological Forecasting and Social Change, Vol. 146, October 2018, pp. 119-132, doi: 10.1016/j.techfore.2019.05.021.

Horvath, D., Csontos, R.S. and Szabó, R.Z. (2018), "Management aspects of smart manufacturing", WMSCI 2018-22nd World Multi-Conference on Systemics, Cybernetics and Informatics, Proceedings, Wmsci, Vol. 2, pp. 168-172.

Islam, A. and Tedford, D. (2012), "Risk determinants of small and medium-sized manufacturing enterprises (SMEs) - an exploratory study in New Zealand", Journal of Industrial Engineering International, Vol. 8 No. 1, pp. 1-13, doi: 10.1186/2251-712X-8-12.

Kaasinen, E., Aromaa, S., Heikkiläl, P. and Liinasuo, M. (2019), "Empowering and engaging solutions for operator 4.0", IFIP International Conference on Advances in Production Management Systems, Vol. 1, pp. 615-623, doi: 10.1007/978-3-030-30000-5.

Kallio, H., Pietilä, A.M., Johnson, M. and Kangasniemi, M. (2016), "Systematic methodological review: developing a framework for a qualitative semi-structured interview guide", Journal of Advanced Nursing, Vol. 72 No. 12, pp. 2954-2965, doi: 10.1111/jan.13031.

Klumpp, M., Hesenius, M., Meyer, O., Ruiner, C. and Gruhn, V. (2019), "Production logistics and human-computer interaction-state-of-the-art, challenges and requirements for the future", International Journal of Advanced Manufacturing Technology, Vol. 105 No. 9, pp. 3691-3709, doi: 10.1007/s00170-019-03785-0.

Kotter, J. and Schlesinger, L. (2008), “Choosing strategies for change”, Harvard Business Review, Vol. 57, pp. 106-114.

Kumar, K., Zindani, D. and Davim, J.P. (2019), "Industry 4.0 developments towards the fourth industrial revolution”, in Industry 4.0, Vol. 0, pp. 27-33, doi: 10.1007/978-981-13-8165-2.

Lasi, H., Fettke, P., Kemper, H.G., Feld, T. and Hoffmann, M. (2014), "Industry 4.0", Business and Information Systems Engineering, Vol. 6 No. 4, pp. 239-242, doi: 10.1007/s12599-014-0334-4.

Le Grand, T. and Deneckere, R. (2019), "COOC: an agile change management method", Proceedings - 21st IEEE Conference on Business Informatics, CBI 2019, Vol. 2, pp. 28-37, doi: 10.1109/CBI.2019.10093.

Lee, J., Bagheri, B. and Kao, H.A. (2015), "A cyber-physical systems architecture for industry 4.0-based manufacturing systems", Manufacturing Letters, Vol. 3, pp. 18-23, doi: 10.1016/j.mfglet.2014.12.001.

Lee, J., Jin, C. and Bagheri, B. (2017), "Cyber physical systems for predictive production systems”, Production Engineering, Vol. 11 No. 2, pp. 155-165, doi: 10.1007/s11740-017-0729-4.

Loch, F., Quint, F. and Brishtel, I. (2016), "Comparing video and augmented reality assistance in manual assembly", Proceedings - 12th International Conference on Intelligent Environments, IE 2016, pp. 147-150, doi: 10.1109/IE.2016.31.

Merhar, L., Berger, C., Braunreuther, S. and Reinhart, G. (2019), "Digitization of manufacturing companies: employee acceptance towards mobile and wearable devices", International Conference on Applied Human Factors and Ergonomics, Vol. 795, August 2019, pp. 187-197, doi: 10.1007/978-3-319-94619-1.

Moeuf, A., Pellerin, R., Lamouri, S., Tamayo-giraldo, S., Moeuf, A., Pellerin, R., Lamouri, S. and Tamayo-, S. (2018), "The industrial management of SMEs in the era of industry 4.0", International Journal of Production Research, Vol. 7543, doi: 10.1080/00207543.2017.1372647.

Mora Sanchez, D.O. (2019), "Corporate social responsibility challenges and risks of Industry 4.0 technologies: a review", Smart Sys Tech 2019 - European Conference on Smart Objects, Systems and Technologies, pp. 48-55.

Müller, J., Kiel, D. and Voigt, K. (2018), "What drives the implementation of Industry 4.0? The role of opportunities and challenges in the context of sustainability", Sustainability. doi: 10.10.3390/ su10010247.

Production disturbance management 
JMTM 32,9

302

Mulrow, C.D. (1994), "Rationale for systematic reviews", British Medical Journal, Vol. 309 No. 6954, pp. 597-599, doi: 10.1136/bmj.309.6954.597.

Myers, M.D. and Newman, M. (2007), "The qualitative interview in IS research: examining the craft", Information and Organization, Vol. 17 No. 1, pp. 2-26, doi: 10.1016/j.infoandorg.2006.11.001.

Ochs, T. and Riemann, U. (2016), "Industry 4.0: how to manage transformation as the new normal", in The Palgrave Handbook of Managing Continuous Business Transformation, pp. 1-610, doi: 10. 1057/978-1-137-60228-2.

Pardo Del Val, M. and Martínez Fuentes, C. (2003), "Resistance to change: a literature review and empirical study”, Management Decision, Vol. 41 No. 2, pp. 148-155, doi: 10.1108/00251740310457597.

Pejic-Bach, M., Bertoncel, T., Meško, M. and Krstić, Ž. (2020), "Text mining of Industry 4.0 job advertisements", International Journal of Information Management, Vol. 50, December 2018, pp. 416-431, doi: 10.1016/j.ijinfomgt.2019.07.014.

Petticrew, M. and Roberts, H. (2008), "Systematic reviews in the social sciences”, in Systematic Reviews in the Social Sciences, Vol. 42 No. 5, doi: 10.1002/9780470754887.

Piderit, S.K. (2000), "Rethinking resistance and recognizing ambivalence: a multidimensional view of attitudes toward an organizational change", The Academy of Management Review, Vol. 25 No. 4, p. 783 , doi: $10.2307 / 259206$.

Pradhan, A. and Agwa-Ejon, J. (2018), "Opportunities and challenges of embracing smart factory in South Africa”, PICMET 2018 - Portland International Conference on Management of Engineering and Technology, pp. 1-8, doi: 10.23919/PICMET.2018.8481968.

Reis, M.S. and Gins, G. (2017), "Industrial process monitoring in the big data/Industry 4.0 era: from detection, to diagnosis, to prognosis", Processes, Vol. 5 No. 3, doi: 10.3390/pr5030035.

Romero, D. and Flores, M. (2019), "Proceedings - 2019 IEEE international conference on engineering, technology and innovation, ICE/ITMC 2019”, Proceedings - 2019 IEEE International Conference on Engineering, Technology and Innovation, ICE/ITMC 2019.

Santos, R.C. and Martinho, J.L. (2020), “An Industry 4.0 maturity model proposal”, Journal of Manufacturing Technology Management, Vol. 31 No. 5, pp. 1023-1043, doi: 10.1108/JMTM-09-2018-0284.

Schallock, B., Rybski, C., Jochem, R. and Kohl, H. (2018), "Learning Factory for Industry 4.0 to provide future skills beyond technical training", 8th Conference on Learning Factories 2018 - Advanced Engineering Education and Training for Manufacturing Innovation, Vol. 23, No. 2017, pp. 27-32, doi: 10.1016/j.promfg.2018.03.156.

Schuldt, J. and Friedemann, S. (2017), "The challenges of gamification in the age of industry 4.0: focusing on man in future machine-driven working environments", IEEE Global Engineering Education Conference, EDUCON, April, pp. 1622-1630, doi: 10.1109/EDUCON.2017.7943066.

Schumacher, A., Erol, S. and Sihn, W. (2016), "A maturity model for assessing Industry 4.0 readiness and maturity of manufacturing enterprises”, Procedia CIRP, Vol. 52, pp. 161-166, doi: 10.1016/j. procir.2016.07.040.

Seuring, S. and Gold, S. (2012), "Conducting content-analysis based literature reviews in supply chain management”, Supply Chain Management, Vol. 17 No. 5, pp. 544-555, doi: 10.1108/ 13598541211258609 .

Snow, C.C., Fjeldstad, Ø.D. and Langer, A.M. (2017), "Designing the digital organization", Journal of Organization Design, Vol. 6 No. 1, pp. 7-8, doi: 10.1186/s41469-017-0017-y.

Snyder, H. (2019), "Literature review as a research methodology: an overview and guidelines", Journal of Business Research, Vol. 104, July, pp. 333-339, doi: 10.1016/j.jbusres.2019.07.039.

Stokes, D. and Bergin, R. (2006), "Methodology or 'methodolatry'? An evaluation of focus groups and depth interviews", Qualitative Market Research, Vol. 9 No. 1, pp. 26-37, doi: 10.1108/13522750610640530.

Thoben, K., Wiesner, S. and Wuest, T. (2017), "Industrie 4.0' and smart manufacturing - a review of research issues and application examples", International Journal of Automation Technology, Vol. 11 No. 1, pp. 4-16. 
Thomé, A.M.T., Scavarda, L.F. and Scavarda, A.J. (2016), "Conducting systematic literature review in operations management”, Production Planning and Control, Vol. 27 No. 5, pp. 408-420, doi: 10. 1080/09537287.2015.1129464.

Toulouse, G. (2002), "Accident risks in disturbance recovery in an automated batch-production system”, Human Factors and Ergonomics in Manufacturing, Vol. 12 No. 4, pp. 383-406, doi: 10. 1002/hfm.10020.

Voss, C., Tsikriktsis, N. and Frohlich, M. (2002), "Case research in operations management", International Journal of Operations and Production Management, Vol. 22 No. 2, doi: 10.1108/ 01443570210414329.

Webster, J. and Watson, R.T. (2002), "Analyzing the past to prepare for the future: writing a literature review”, MIS Quarterly, Vol. 26 No. 2, pp. xiii-xxiii.

Whysall, Z., Owtram, M. and Brittain, S. (2019), "The new talent management challenges of industry 4.0", Journal of Management Development, Vol. 38 No. 2, pp. 118-129, doi: 10.1108/JMD-062018-0181.

Wittig, C. (2012), "Employees' reactions to organizational change", OD Practitioner, Vol. 44 No. 2, pp. 23-28, doi: 10.1177/0021886316655871.

Xing, F., Peng, G., Liang, T., Zuo, S. and Li, S. (2019), "Managing changes initiated by industrial big data technologies: a technochange management model", LNCS, International Conference on Human-Computer Interaction, Vol. 11587, pp. 75-87, doi: 10.1007/978-3-030-21935-2_7.

Xu, L.D., Xu, E.L. and Li, L. (2018), "Industry 4.0: state of the art and future trends", International Journal of Production Research, Vol. 56 No. 8, pp. 2941-2962, doi: 10.1080/00207543.2018. 1444806.

Ylipää, T., Skoogh, A., Bokrantz, J. and Gopalakrishnan, M. (2017), "Identification of maintenance improvement potential using OEE assessment", International Journal of Productivity and Performance Management, Vol. 66 No. 1, pp. 126-143, doi: 10.1108/IJPPM-01-2016-0028.

Zheng, T., Ardolino, M., Bacchetti, A., Perona, M. and Zanardini, M. (2020), "The impacts of Industry 4.0: a descriptive survey in the Italian manufacturing sector", Journal of Manufacturing Technology Management, Vol. 31 No. 5, pp. 1085-1115, doi: 10.1108/JMTM-08-2018-0269.

Zimmermann, V., Heimicke, J., Albers, A. and Reiß, N. (2019), “Acceptance modelling in product development - case study: connected systems for Industry 4.0 solutions", IOP Conference Series: Materials Science and Engineering, Vol. 520 No. 1, pp. 0-10, doi: 10.1088/1757-899X/520/1/ 012011.

\section{Corresponding author}

Adriana Ito can be contacted at: adriana.ito@chalmers.se
Production disturbance management 